ISBN 978-93-84468-92-7

International Conference on Issues in Education, Literature, Humanities and Social Sciences

(IELHSS-2017)

Kuala Lumpur (Malaysia) Jan. 4-5, 2017

\title{
The Development of Service Quality of Cafeteria at Kasem Bundit University, Romklao Campus, Bangkok
}

\author{
Dr. Chinnaso Visitnitikija, and Zhubing Gong \\ Post Graduate School of Business Administration, Kasembundit University, Bangkok
}

\begin{abstract}
The purpose of this study is to determine the factors affecting the service and the development of service quality satisfaction of cafeteria at Kasem Bundit University, Romklao campus. This study was the quantitative study with the samplings for the study were 400 respondents who were students and university staff by using a questionnaire as a tool. The statistics used for data analysis were percentage, mean, standard deviation, $t$-test, one-way Anova, and regression analysis.

Findings from the survey indicated that most of respondents were females, under graduated students, single marital status, and age 22-25 years old. The overall average picture of the opinions of factors affecting service quality of staff were at medium level consisted of respond to customer aspect, reliability aspect, confidence aspect, attention aspect, and tangible services. The overall picture of the opinions of factors of personal different, such as gender affected service satisfaction of cafeteria at Kasem Bundit University, Romklao campus at significant level 0.05. Factors of quality, reliability, dependable, pay attention to customer, and tangible services correlated to service satisfaction of cafeteria at Kasem Bundit University, Romklao campus at significant level 0.05.

Recommendations from this study were that store owners should develop quality of foods such as taste, variety of beverages, select raw materials with best quality, maintain level of services, pay attention to customers and services, remember what repeated customer want, and services with courtesy.
\end{abstract}

Keywords: Development Quality

\section{Introduction}

A cafeteria is a type of food service location in which there is little or no waiting staff table service, whether a restaurant or within an institution such as a large office building or school; a school dining location is also referred to as a dining hall or canteen (in British English). ${ }^{1}$ Cafeterias are different from coffeehouses, despite being the Spanish translation of the English term.

Instead of table service, there are food-serving counters/stalls, either in a line or allowing arbitrary walking paths. Customers take the food they require as they walk along, placing it on a tray. In addition, there are often stations where customers order food and wait while it is prepared, particularly for items such as hamburgers or tacos which must be served hot and can be immediately prepared. Alternatively, the patron is given a number and the item is brought to their table. For some food items and drinks, such as sodas, water, or the like, customers collect an empty container, pay at the check-out, and fill the container after the check-out. Free unlimited second servings are often allowed under this system. For legal purposes (and the consumption patterns of customers), this system is rarely, if at all, used for alcoholic beverages in the US.

Customers are either charged a flat rate for admission (as in a buffet) or pay at the check-out for each item. Some self-service cafeterias charge by the weight of items on a patron's plate. In universities and colleges, some students pay for three meals a day by making a single large payment for the entire semester.

\footnotetext{
1 "Cafeteria". Merriam Webster. Retrieved 2012-05-19.
} 
As cafeterias require few employees, they are often found within a larger institution, catering to the clientele of that institution. For example, schools, colleges and their residence halls, department stores, hospitals, museums, military bases, prisons, and office buildings often have cafeterias.

In American English, a college cafeteria is a cafeteria intended for college students. In British English it is often called the refectory. These cafeterias can be a part of a residence hall or in a separate building. Many of these colleges employ their own students to work in the cafeteria. The number of meals served to students varies from school to school, but is normally around 21 meals per week. Like normal cafeterias, a person will have a tray to select the food that he or she wants, but (at some campuses) instead of paying money, pays beforehand by purchasing a meal plan.

The method of payment for college cafeterias is commonly in the form of a meal plan, whereby the patron pays a certain amount at the start of the semester and details of the plan are stored on a computer system. Student ID cards are then used to access the meal plan. Meal plans can vary widely in their details and are often not necessary to eat at a college cafeteria. Typically, the college tracks students' usage of their plan by counting the number of predefined meal servings, points, dollars, or number of buffet dinners. The plan may give the student a certain number of any of the above per week or semester and they may or may not roll over to the next week or semester. ${ }^{2}$

Many schools offer several different options for using their meal plans. The main cafeteria is usually where most of the meal plan is used but smaller cafeterias, cafés, restaurants, bars, or even fast food chains located on campus, on nearby streets, or in the surrounding town or city may accept meal plans. A college cafeteria system often has a virtual monopoly on the students due to an isolated location or a requirement that residence contracts include a full meal plan. It is not uncommon for the entire food service operation to be outsourced to a managed services company.

\section{The Purpose of the Study}

1. To study factors affecting service quality of Cafeteria at Kasem Bundit University, Romklao campus.

2. To study service satisfaction of personnel of cafeteria at Kasem Bundit University, Romklao campus.

\section{Conceptual framework of the study}

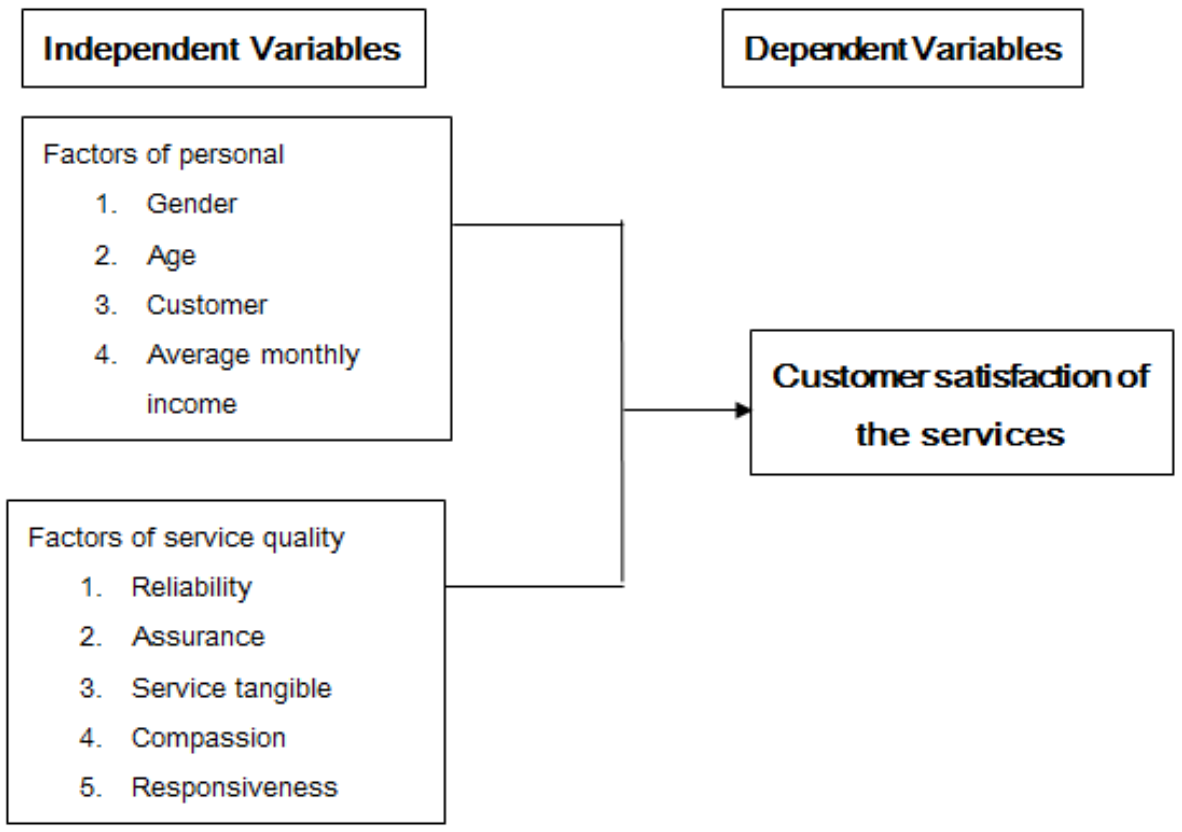

From figure 1: shows the overall picture of the opinions of customer on service satisfaction of cafeteria at Kasem Bundit University, Romklao campus were at medium level consisted of responsive to customer aspect $(\bar{x}=3.28)$,

2 "Helping Your College Student Select a Meal Plan". College parents. 
service tangible aspect $(\bar{x}=3.23)$, assurance aspect $(\bar{x}=3.21)$, empathy aspect $(\bar{x}=3.20)$, and reliability aspect $(\bar{x}=3.18)$.

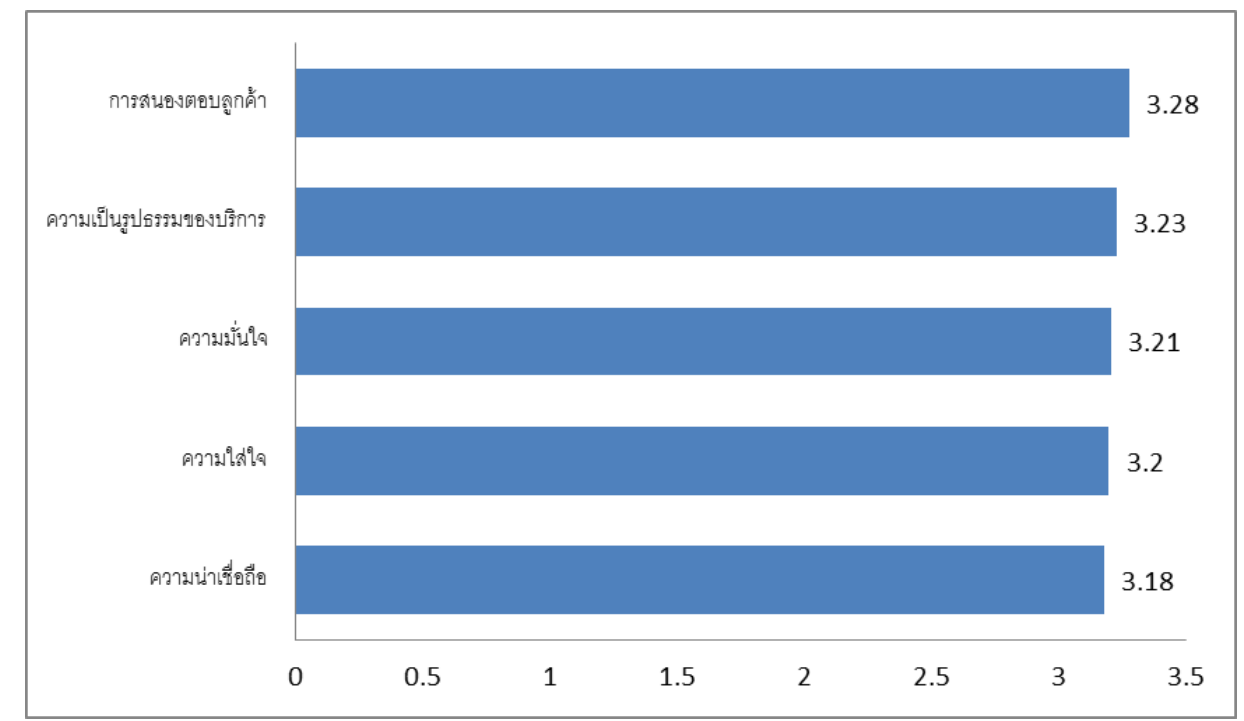

Fig. 1: level of services quality of Cafeteria at Kasem Bundit University, Romklao campus

\section{Summary of the Results}

The purpose of this study is to determine the factors affecting the service and the development of service quality satisfaction of cafeteria at Kasem Bundit University, Romklao campus. This study was the quantitative study with the samplings for the study were 400 respondents who were students and university staff by using a questionnaire as a tool. The statistics used for data analysis were percentage, mean, standard deviation, t-test, one-way Anova, and regression analysis.

1. Factors of personal

Findings indicated that most of respondents were females, age 22-25 year old, under graduate students, monthly income 10,000-30,000 baht.

2. Factors affecting service quality of cafeteria at Kasem Bundit University, Romklao campus.

The overall picture of the opinions of factors affecting service quality of cafeteria at Kasem Bundit University were at medium level with details as follows:

For reliability aspect, a variety of healthy foods and beverages with standard quality.

The responsiveness aspect, delivery with accurately orders, fast services, and staff are always ready to take an order

The assurance aspect, staff will service with enthusiasm, honest, courtesy, and service standard.

The compassion aspect, suggestion new menu items, wear proper uniform, wear aprons, and recognizes customer with special diet.

The tangible services, staff wear neatly uniforms, listen to comments, and pleasurable area environment with hygiene.

3. The overall picture of the opinions of service satisfaction of cafeteria at Kasem Bundit University, Romklao campus.

4. The test of hypothesis revealed that the personal different such as gender affected the service satisfaction of cafeteria at Kasem Bundit University, Romklao campus with significant level 0.05. Factors of reliability aspect, assurance aspect, service tangible, empathy, and responsiveness correlated to customer satisfaction of cafeteria at Kasem Bundit University with significant level 0.05 .

\section{Discussion of Study Results}

The study of the factors affecting the service and the development of service quality satisfaction of cafeteria at Kasem Bundit University, Romklao campus with the overall picture of the opinions were at medium level with corresponded to Daranee Kongeard.(2554). 
For reliability aspect, a variety of healthy foods and beverages with standard quality with the overall picture of the opinions were at medium level with corresponded to Daranee Kongeard. (2554).

The responsiveness aspect, delivery with accurately orders, fast services, and staff are always ready to take an order with the overall picture of the opinions were at medium level with corresponded to Daranee Kongeard. (2554).

The assurance aspect, staff will service with enthusiasm, honest, courtesy, and service standard with the overall picture of the opinions were at medium level with corresponded to Daranee Kongeard. (2554).

The compassion aspect, suggestion new menu items, wear proper uniform, wear aprons, and recognizes customer with special diet with the overall picture of the opinions were at medium level with corresponded to Niramon Janongsri.(2549).

The tangible services, staff wear neatly uniforms, listen to comments, and pleasurable area environment with hygiene with the overall picture of the opinions were at medium level with corresponded to Niramon Janongsri. (2549).

\section{References}

[1] Niramon Janongsri. (2549). Customer satisfaction \& behavior of services of cafeteria at Mahasarakarm University

[2] Daranee Kongeard. (2554). Service quality of personnel of employees at Ratchamongkol Technology Tanyaburi University.

[3] Nantatee Pengpoom. (2547). Problem of service of employee's cafeteria at Ministry of education

[4] Pichase Lumpanupat. (2545). Factors affecting tourists decision of choosing restaurant in capital district, Chiengmai province.

[5] Unchalee Vongvibulkul. (2546). Consumer behavior on eating Japanese food in Bangkok.

[6] Jeeranun Jeennium. (2550). Factors affecting consumer decision on choosing cafeteria at Finance department.

"Cafeteria". Merriam Webster. Retrieved 2012-05-19.

[7] "Helping Your College Student Select a Meal Plan". College parents. 